\title{
Safety of Prophylactic Heparin in the Prevention of Venous Thromboembolism After Spontaneous Intracerebral Hemorrhage: A Meta-analysis
}

\author{
$\mathrm{Xi}_{\operatorname{Pan}^{1, *}} \quad$ Jihui Li $\mathrm{Li}^{2, *} \quad$ Lan $\mathrm{Xu}^{3} \quad$ Shengming Deng ${ }^{2}$ \\ ${ }^{1}$ Departments of Neurology, The First Affiliated Hospital of Soochow \\ University, Suzhou, Jiangsu, People's Republic of China \\ 2 Department of Nuclear Medicine, The First Affiliated Hospital of \\ Soochow University, Suzhou, Jiangsu, People's Republic of China \\ ${ }^{3}$ Department of Nursing, The First Affiliated Hospital of Soochow \\ University, Suzhou, Jiangsu, People's Republic of China
}

\author{
Zhi Wang ${ }^{1}$
}

Address for correspondence Lan Xu, BM, Department of Nursing, The First Affiliated Hospital of Soochow University, 899 Pinghai Road, Suzhou, Jiangsu 215000, People's Republic of China (e-mail: xulan1108@sina.com).

J Neurol Surg A 2020;81:253-260.

\begin{abstract}
\section{Keywords}

- heparin

- prophylactic

- intracerebral hemorrhage

- venous thromboembolism

Objectives Patients with spontaneous intracerebral hemorrhage $(\mathrm{sICH})$ have a nearly fourfold greater risk for venous thromboembolism (VTE) than those with acute ischemic stroke, and VTE after sICH is associated with high risk for in-hospital mortality. The benefit from prophylactic heparin for VTE remains uncertain because its safety is not documented. In this study, we used an updated meta-analysis to evaluate the safety of heparin for the prevention of VTE in patients with $\mathrm{sICH}$.

Methods Electronic databases Medline and Embase from January 1990 to November 2017 and the Cochrane Library were searched using these keywords: intracerebral hemorrhage, stroke, hemorrhagic stroke, subarachnoid hemorrhage, heparin, heparinoids, low-molecularweight heparin, anticoagulants, prophylactic, low dose, prevention, deep venous thrombosis, pulmonary embolism, venous thrombosis, randomized controlled trial, controlled clinical trial, and outcome. We evaluated the quality of included studies according to the bias risk in the Cochrane Handbook for Systematic Reviews of Interventions v.5.1.0. All statistical analyses were performed with RevMan v.5 software (Cochrane Collaboration, London, United Kingdom). Tests of heterogeneity were conducted with the Mantel-Haenszel method.

Results Nine studies involving 4,055 patients with sICH met the inclusion criteria in this meta-analysis. Of these studies, only one met all specific criteria and had a low probability of bias, whereas eight studies met only some of the criteria and had a moderate probability of bias. In comparison with non-heparin treatments, low-molecular-weight heparin or unfractionated heparin was associated with a nonsignificant increase in any hematoma enlargement, a nonsignificant reduction in extracranial hemorrhage, a nonsignificant increase in mortality, a nonsignificant increase in the number of modified Rankin Scale scores of 3 to 5 , and a nonsignificant increase in numbers of Glasgow Outcome Scale scores of 2 to 3.

Conclusion Prophylactic heparin was associated with a nonsignificant increase in any hematoma enlargement and mortality, a nonsignificant reduction in extracranial hemorrhage, and a nonsignificant increase in the incidence of major disability in patients with $\mathrm{sICH}$. It is probably safe to administer heparin to prevent VTE in patients with $\mathrm{sICH}$.
\end{abstract}

Xi Pan and Jihui Li contributed equally to this article as first coauthors.

received

January 11, 2019

accepted after revision

July 3, 2019

published online

January 21, 2020 (c) 2020 Georg Thieme Verlag KG

Stuttgart · New York
DOI https://doi.org/

10.1055/s-0039-3400497. ISSN 2193-6315. 


\section{Introduction}

It was reported that as high as $40 \%$ of patients with ischemic stroke are at particularly high risk for venous thromboembolism (VTE) because of restricted mobility. ${ }^{1}$ Acute spontaneous intracerebral hemorrhage ( $\mathrm{sICH}$ ) is an independent risk factor for VTE, and patients with sICH have a nearly fourfold greater risk for VTE than those with acute ischemic stroke. ${ }^{2}$ VTE is associated with increased rates of mortality and morbidity. Prevention of VTE is better than treatment of it. Up to 75\% of patients with stroke and resulting hemiplegia develop deep venous thrombosis (DVT) if they are not placed on prophylactic medication because weakness of the lower limb leads to alterations in blood flow and a hypercoagulable state. Most deaths from VTE are attributable to preventable negligence, rather than to failure of treatment. Reasonable precautions can reduce the risk of DVT formation by $63 \%$. 3,4

Prophylaxis for VTE in patients with sICH includes nonpharmacologic and pharmacologic approaches. Common nonpharmacologic prophylactic measures include intermittent pneumatic compression (IPC) and elastic compression stockings (ECS). However, these nonpharmacologic prophylactic measures have certain limitations in clinical practice; for example, they cannot be used in cases of limb deformity, fractured limbs, or heart failure. Multiple organizations in the United States (since 2007), Europe (since 2006), and Japan (since 2011) have recommended that prophylactic doses of heparin be considered for DVT prevention. Prophylactic heparin is not recommended in the United Kingdom or Australia, ${ }^{5}$ however, because of findings that the use of heparin will cause an enlargement of hematomas and may even increase rates of mortality.

A meta-analysis of four controlled studies suggested a significant reduction in pulmonary embolism (PE) with heparin. ${ }^{6}$ In a trial that involved 68 patients with $\mathrm{sICH}$, heparin initiation on day 2 resulted in a statistically lower rate of PE than did initiation on day 4 or day $10 .^{7}$ However, the safety of early initiation of prophylactic heparin in the prevention of VTE in patients with sICH is uncertain. Results of a randomized study in 1991 suggested that early use of heparin in ICH patients prevented DVT without increased intracranial hemorrhage. ${ }^{7} \mathrm{~A}$ more recent trial involving 103 patients demonstrated that subcutaneous enoxaparin does not increase the risk of rebleeding or hematoma expansion. ${ }^{8}$ In contrast, Orken et al, ${ }^{9}$ Wasay et al, $^{10}$ and Tetri et $\mathrm{al}^{11}$ found that hematoma enlargements occurred more often in the patients who received heparin, although the difference was not statistically significant. The European Stroke Organization (2014) ${ }^{12}$ and the American Heart Association (2015) $)^{13}$ stated that the safety of prophylactic doses of heparin for DVT prevention remains uncertain.

To clarify the safety of prophylactic heparin in the prevention of VTE in patients with sICH, we performed an updated metaanalysis of studies (randomized or not) in which low-molecular-weight heparin (LMWH) or unfractionated heparin (UFH) was compared with non-heparin treatments. Study outcomes included any hematoma enlargement, major extracranial hemorrhage, and major disability as defined by modified Rankin Scale (mRS) scores of 3 to 5 or Glasgow Outcome Scale (GOS) scores of 2 to 3 and death.

\section{Methods}

We prospectively developed a protocol in which specific objectives, selection criteria, assessment of study quality, clinical outcomes, and statistical methods were compared in detail.

\section{Study Identification}

All relevant comparisons of LMWH or UFH with non-heparin treatments for prevention of VTE in patients with SICH that were published from January 1990 to November 2017 were identified from electronic databases (Medline and Embase), as well as from the Cochrane Library. Keywords were intracerebral hemorrhage, stroke, hemorrhagic stroke, subarachnoid hemorrhage, heparin, heparinoids, low-molecular-weight heparin, prophylactic, low dose, anticoagulants, prevention, deep venous thrombosis, pulmonary embolism, venous thrombosis, randomized controlled trial, controlled clinical trial, and outcome. The relevance of studies to the prevention of VTE after sICH was determined on the basis of title, abstract, and full manuscript. If any of these data were not available in a particular publication, further information was sought through correspondence with the authors of the reference.

\section{Study Selection}

Inclusion criteria were as follows: (1) patient: patients with spontaneous intracerebral hemorrhage; (2) intervention: LMWH or UFH treatment, or LMWH or UFH treatment plus non-heparin therapy (IPC, ECS, or placebo); (3) comparison: non-heparin treatment (IPC, ECS, or placebo); (4) outcome: any hematoma enlargement, major extracranial hemorrhage, and major disability as defined by mRS scores of 3 to 5 or GOS scores of 2 to 3 and death; and (5) prophylactic doses of LMWH ( $\leq 40 \mathrm{mg} /$ day) or UFH $(5,000$ IU/8 hours or less). Exclusion criteria were $\mathrm{ICH}$ caused by surgery or traumatic brain injury, noncontrolled studies, animal experiments, case studies, reviews, and appraised topics.

\section{Study Quality}

The quality of studies was evaluated according to the bias risk described in the Cochrane Handbook for Systematic Reviews of Interventions, v.5.1.0. ${ }^{14}$ The evaluation parameters included random sequence (selection bias), degree of hidden (performance) bias, use of blind methods for implementers and participants (detection bias), use of blind methods for outcome evaluator (loss to follow-up bias), incomplete data report (attrition bias), selective reporting data (reporting bias), and other bias (other bias). If a study referred to all these criteria and indicated low risk of bias, its quality was considered "A"; if a study met part of the criteria and the probability of bias was moderate, its quality was considered "B." If a study did not meet the any of the criteria, indicating the possibility of a high risk of bias, its quality was considered "C."

\section{Data Extraction}

Two investigators independently extracted data on study design, study quality, and the following safety outcomes within 3 months: (1) population (inclusion and exclusion criteria, sample size); (2) intervention (LMWH or UFH, 
treatment initiation, duration of treatment, dose of heparin, comparator); and (3) study outcomes (any hematoma enlargement, major extracranial hemorrhage, death, and major disability according to mRS scores of 3-5 or GOS scores of 2-3). The data abstracted for each trial were confirmed by a third investigator, and any disagreements were resolved by consensus.

\section{Statistical Analysis}

All statistical analyses were performed with RevMan v.5 software (Cochrane Collaboration, London, United Kingdom). Tests of heterogeneity were conducted with the MantelHaenszel method. A $p$ value $\leq 0.05$ was considered statistically significant except in heterogeneity testing, for which a $p$ value of 0.10 was accepted as statistically significant. If $p>0.10$ and the proportion of variation across studies that was due to heterogeneity $\left(\mathrm{I}^{2}\right)$ was $<50 \%$, a fixed-effects model was used. If $p>0.10$ and $\mathrm{I}^{2} \geq 50 \%$, a random-effects model based on the Mantel-Haenszel method was used to combine results from individual studies. If $p>0.10$ and the source of the heterogeneity could not be judged, the descriptive analysis was used. In addition, the risk ratios (RRs) and 95\% confidence intervals (CIs) were calculated.

\section{Results}

\section{Study Selection}

-Fig. 1 illustrates the process of study selection. From a database search of citations, 1,443 records were identified, and 9 additional records were identified through other sources. Of these records, 684 were retained for further evaluation after duplicates were removed. After screening of titles and abstracts, 668 citations were excluded, and 17 citations were retained for further evaluation. Eight additional studies were excluded for these reasons: One study was a critically appraised topic ${ }^{15}$; a control group was not included in three studies $^{16-18}$; one study was not a controlled study of heparin and other measures ${ }^{19}$; IPC, ECS, and placebo were not used in the control group in one study ${ }^{20}$; and ICH was caused by traumatic brain injury in two studies. ${ }^{21,22}$ - Table 1 summarizes the designs of the nine studies ${ }^{7-11,23-26}$ included in this meta-analysis.

\section{Study Quality}

- Table 2 summarizes the quality data of the nine studies. Of these studies, only one study was of "A" quality; the other eight studies were of "B" quality. Most studies were deficient

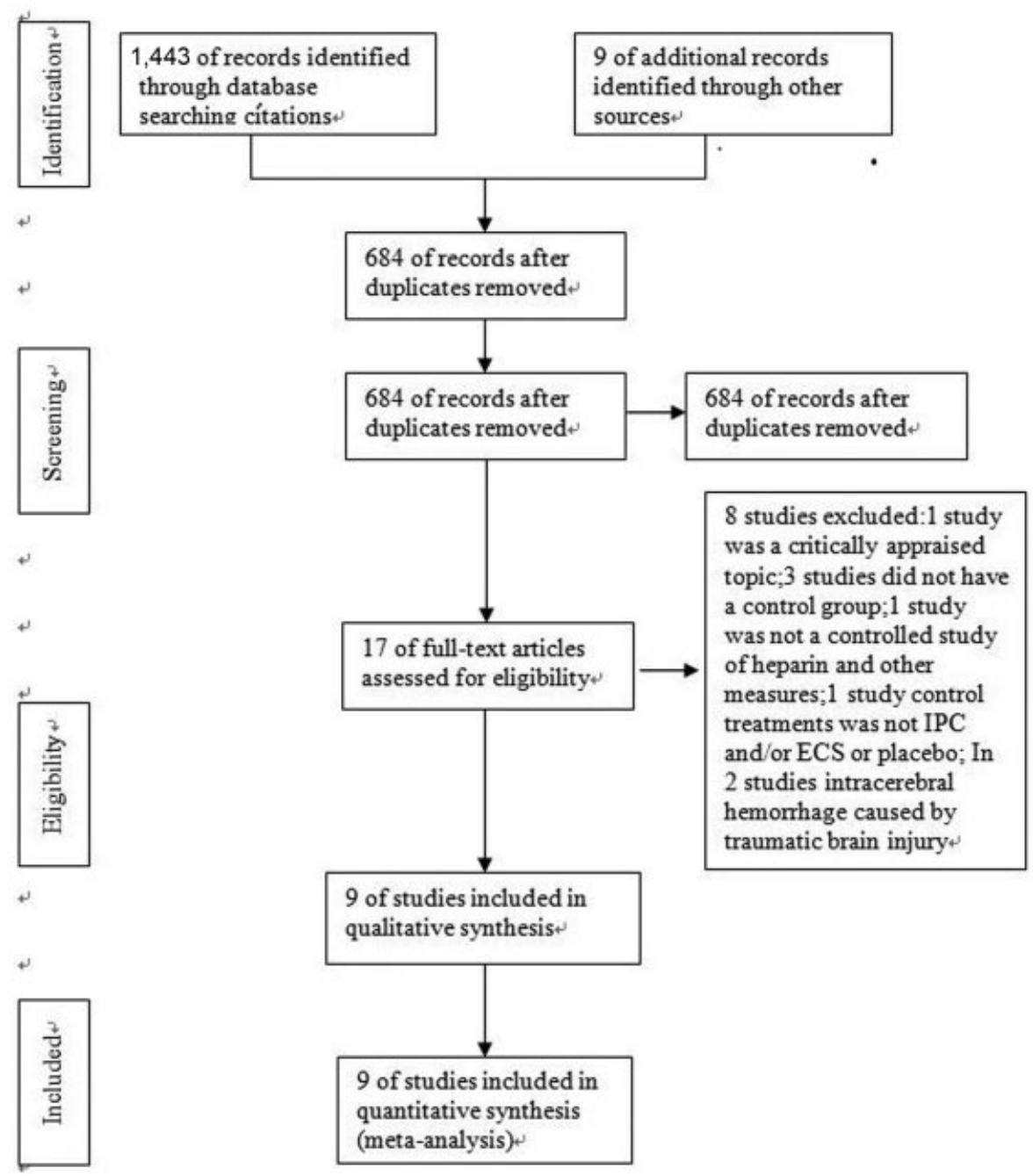

Fig. 1 Process of study selection. ECS, elastic compression stockings; IPC, intermittent pneumatic compression. 
Table 1 Characteristics of studies included in the meta-analysis

\begin{tabular}{|l|l|l|l|l|l|l|l|}
\hline Study & Treatment & $\begin{array}{l}\text { Treatment } \\
\text { initiation }\end{array}$ & $\begin{array}{l}\text { Duration of } \\
\text { treatment }\end{array}$ & Dose & Control & Follow-up & Outcomes \\
\hline Paula $^{23}$ & $\begin{array}{l}\text { UFH or } \\
\text { LMWH }\end{array}$ & $7 \mathrm{~d}$ & NR & Prophylactic & Placebo & $90 \mathrm{~d}$ & mRS; death \\
\hline Yu $^{8}$ & LMWH & $1 \mathrm{~d}$ & $14 \mathrm{~d}$ & $4,000 \mathrm{IU} / \mathrm{d}$ & Placebo & $14 \mathrm{ds}$ & $\begin{array}{l}\text { Hematoma enlargement; } \\
\text { death }\end{array}$ \\
\hline Gu et al & $\begin{array}{l}\text { LMWH } \\
\text { and IPC }\end{array}$ & $4 \mathrm{~d}$ & $10 \mathrm{~d}$ & $0.4 \mathrm{~mL} / \mathrm{d}$ & IPC & $14 \mathrm{~d}$ & $\begin{array}{l}\text { Hematoma enlargement; } \\
\text { extracranial hemorrhage; } \\
\text { death }\end{array}$ \\
\hline Orken et al & $\begin{array}{l}\text { LMWH } \\
\text { and CS }\end{array}$ & $48 \mathrm{~h}$ & NR & $40 \mathrm{mg} / \mathrm{d}$ & CS & $21 \mathrm{~d}$ & $\begin{array}{l}\text { Hematoma enlargement; } \\
\text { death }\end{array}$ \\
\hline Wasay et al & $\begin{array}{l}\text { UFH } \\
\text { and CS }\end{array}$ & Day $1-6$ & $7-14 \mathrm{~d}$ & $2,500-5,000 \mathrm{IU} / 12 \mathrm{~h}$ & CS & NR & $\begin{array}{l}\text { Hematoma enlargement; } \\
\text { extracranial hemorrhage; } \\
\text { death }\end{array}$ \\
\hline Tetri et al ${ }^{11}$ & LMWH & $24 \mathrm{~h}$ & NR & $20-40 \mathrm{mg} / \mathrm{d}$ & Placebo & 3 mo & $\begin{array}{l}\text { Hematoma enlargement; } \\
\text { GOS; death }\end{array}$ \\
\hline Wurm et al & LMWH & Day 3 & $3 \mathrm{wk}$ & $20 \mathrm{mg} / \mathrm{d}$ & Placebo & $1 \mathrm{y}$ & $\begin{array}{l}\text { Extracranial hemorrhage; } \\
\text { death }\end{array}$ \\
\hline Siironen et al & LMWH & $24 \mathrm{~h}$ & $10 \mathrm{~d}$ & $40 \mathrm{mg} / \mathrm{d}$ & Placebo & 3 mo & $\begin{array}{l}\text { mRS; GOS; extracranial } \\
\text { hemorrhage; death }\end{array}$ \\
\hline Boeer et al & $\begin{array}{l}\text { UFH } \\
\text { and CS }\end{array}$ & $96 \mathrm{~h}$ & $10 \mathrm{~d}$ & $5,000 \mathrm{IU} / 8 \mathrm{~h}$ & CS & $10 \mathrm{~d}$ & $\begin{array}{l}\text { Hematoma enlargement; } \\
\text { death }\end{array}$ \\
\hline
\end{tabular}

Abbreviations: CS, compression stockings; GOS, Glasgow Outcome Scale; IPC, intermittent pneumatic compression; LMWH, low-molecular-weight heparin; mRS, modified Rankin Scale; NR, not reported; UFH, unfractionated heparin.

Table 2 Quality of studies included in the meta-analysis

\begin{tabular}{|c|c|c|c|c|c|c|c|c|}
\hline & $\begin{array}{l}\text { Selection } \\
\text { bias }\end{array}$ & $\begin{array}{l}\text { Performance } \\
\text { bias }\end{array}$ & $\begin{array}{l}\text { Detection } \\
\text { bias }\end{array}$ & $\begin{array}{l}\text { Attrition } \\
\text { bias }\end{array}$ & $\begin{array}{l}\text { Reporting } \\
\text { bias }\end{array}$ & $\begin{array}{l}\text { Other } \\
\text { reporting } \\
\text { bias }\end{array}$ & $\begin{array}{l}\text { Other } \\
\text { bias }\end{array}$ & Level \\
\hline Paula (2016) & NR & NR & NR & NR & Low bias & Low bias & $N R$ & B \\
\hline Yu (2015) & NR & NR & NR & NR & Low bias & Low bias & NR & B \\
\hline Gu et $a^{24}$ & NR & NR & NR & NR & Low bias & Low bias & NR & B \\
\hline Orken et $\mathrm{al}^{9}$ & NR & NR & Low bias & Low bias & Low bias & Low bias & NR & B \\
\hline Wasay et al ${ }^{10}$ & NR & NR & NR & NR & Low bias & Low bias & NR & B \\
\hline Tetri et al ${ }^{11}$ & NR & NR & Low bias & Low bias & Low bias & Low bias & NR & $B$ \\
\hline Wurm et $\mathrm{al}^{25}$ & Low bias & Low bias & Low bias & Low bias & Low bias & Low bias & NR & A \\
\hline Siironen et $\mathrm{al}^{26}$ & NR & Low bias & Low bias & NR & Low bias & Low bias & NR & B \\
\hline Boeer et $\mathrm{al}^{7}$ & NR & NR & NR & NR & Low bias & Low bias & NR & B \\
\hline
\end{tabular}

Abbreviation: NR, not reported.

in the blind method, and their data reports were incomplete. Although loss to follow-up was reported, an intent-to-treat analysis was not conducted, and the reasons for the loss to follow-up were not explained.

\section{Study Outcomes}

\section{Incidence of Intracranial Hemorrhage}

Six trials that involved 1,082 patients yielded data on ICH (-Fig. 2). There was no statistically significant heterogeneity among the studies $\left(\mathrm{I}^{2}=8 \% ; p=0.36\right)$. In comparison with nonheparin treatments, heparin treatment was associated with a nonsignificant increase in any hematoma enlargement $(6.6 \%$ versus 3.2\%; RR: 1.48 ; 95\% CI, $0.88-2.50 ; p=0.14$ ).

\section{Incidence of Major Extracranial Hemorrhage}

Three trials involving 618 patients yielded data on extracranial hemorrhage (-Fig. 3). There was no statistically significant heterogeneity among the studies $\left(\mathrm{I}^{2}=32 \% ; p=0.22\right)$. In comparison with non-heparin treatments, heparin treatment was associated with a nonsignificant reduction in extracranial hemorrhage ( $1.8 \%$ versus $2.8 \%$; RR: $0.71 ; 95 \% \mathrm{CI}, 0.25-2.05$; $p=0.53)$.

\section{Incidence of Death}

Seven trials involving 3,848 patients yielded data on mortality (-Fig. 4). There was no statistically significant heterogeneity among the studies $\left(\mathrm{I}^{2}=1 \% ; p=0.42\right)$. In comparison with nonheparin treatments, heparin treatment was associated with a 


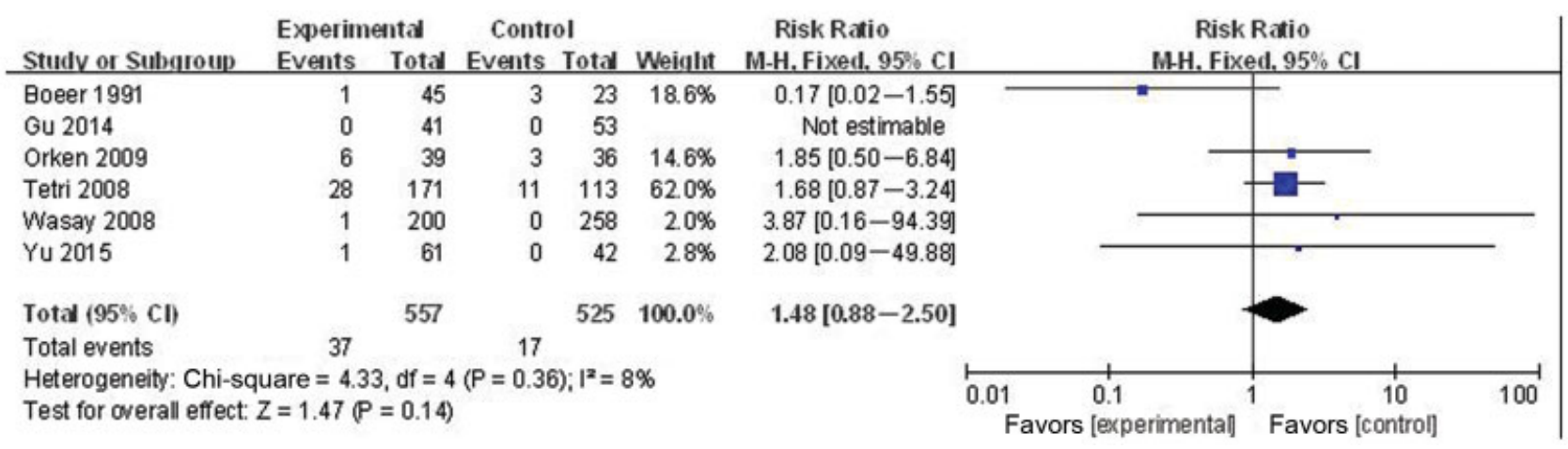

Fig. 2 Any hematoma enlargement in studies comparing low-molecular-weight heparin or unfractionated heparin with non-heparin treatments (elastic compression stockings, intermittent pneumatic compression, or placebo) for the prevention of venous thromboembolism.

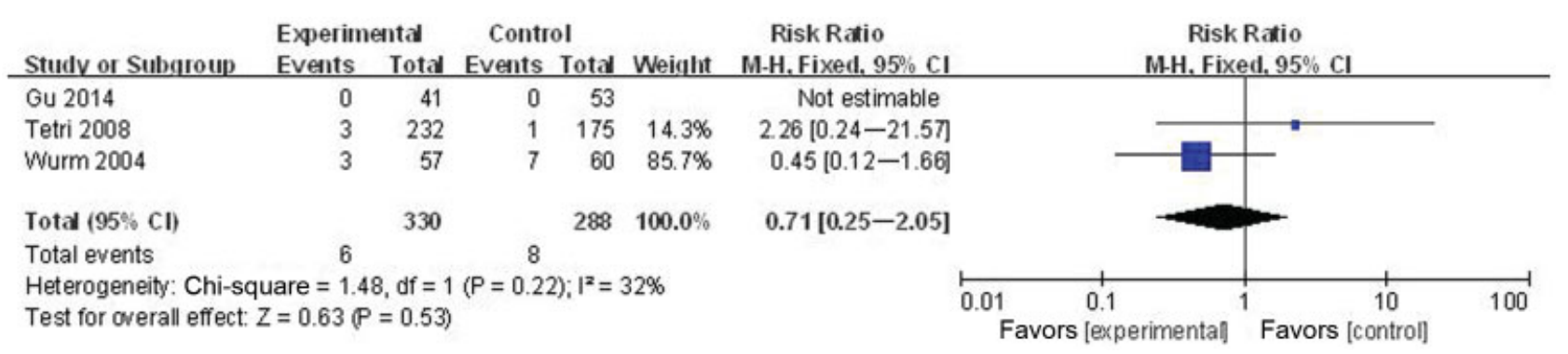

Fig. 3 Any extracranial hemorrhage in studies comparing low-molecular-weight heparin or unfractionated heparin with non-heparin treatments (elastic compression stockings, intermitted pneumatic compression, or placebo) for the prevention of venous thromboembolism. $\mathrm{Cl}$, confidence interval; M-H, Mantel-Haenszel.

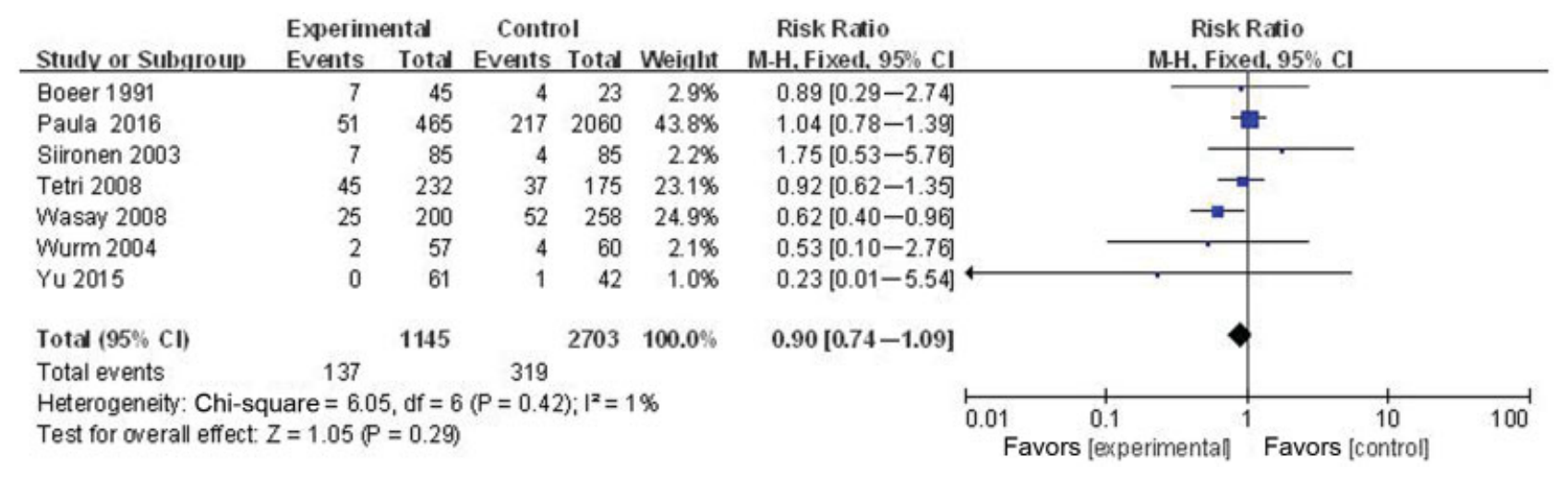

Fig. 4 Death due to any cause in studies comparing low-molecular-weight heparin or unfractionated heparin with non-heparin treatments (elastic compression stockings, intermitted pneumatic compression, or placebo) for the prevention of venous thromboembolism.

nonsignificant increase in mortality (12.0\% versus $11.8 \%$; RR: 0.90; 95\% CI, 0.74-1.09; $p=0.29$ ).

\section{Incidence of Major Disability}

\section{Modified Rankin Scale Scores}

Two trials involving 2,695 patients yielded data on mRS scores (-Fig. 5). There was statistically significant heterogeneity between the studies $\left(\mathrm{I}^{2}=83 \% ; p=0.01\right)$. The randomeffects model was used for analysis. In comparison with nonpharmacologic treatments, heparin treatment was associated with a nonsignificant increase in the numbers of $\mathrm{mRS}$ scores of 3 to 5 ( $58.3 \%$ versus $42.8 \%$; RR: 1.55 ; $95 \%$ CI, $0.57-$ $4.20 ; p=0.39)$.

\section{Glasgow Outcome Scale Scores}

Three trials involving 694 patients yielded data on GOS scores. However, descriptive analysis was used because the observation time point in one study ${ }^{25}$ was different from those in the other studies, and the data in that study could not be combined with the data in other studies for analysis. In Wurm's study, ${ }^{25}$ patients received one subcutaneous injection per day of either $20 \mathrm{mg}$ enoxaparin or placebo for 3 weeks after ICH. Patients treated with enoxaparin had significantly more favorable GOS scores than patients treated with placebo at 1-year follow-up. Moreover, the other two articles were meta-analyzed. There was statistically significant heterogeneity between the studies $\left(\mathrm{I}^{2}=80 \% ; p=0.03\right)$ (-Fig. 6). The random-effects model was used for analysis. In 


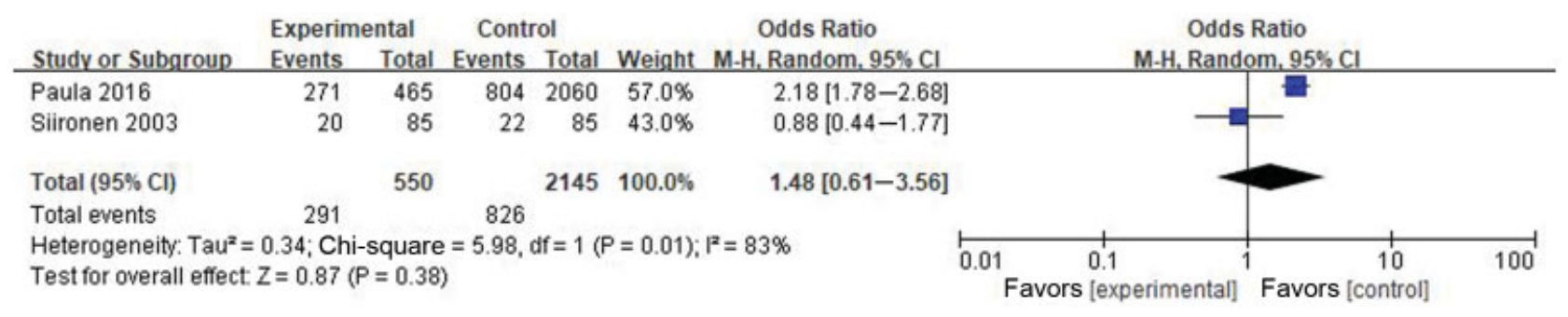

Fig. 5 Major disability at 90 days, according to scores 3 to 5 on the modified Rankin Scale comparing low-molecular-weight heparin or unfractionated heparin with non-heparin treatments (elastic compression stockings, intermitted pneumatic compression, or placebo) for the prevention of venous thromboembolism.

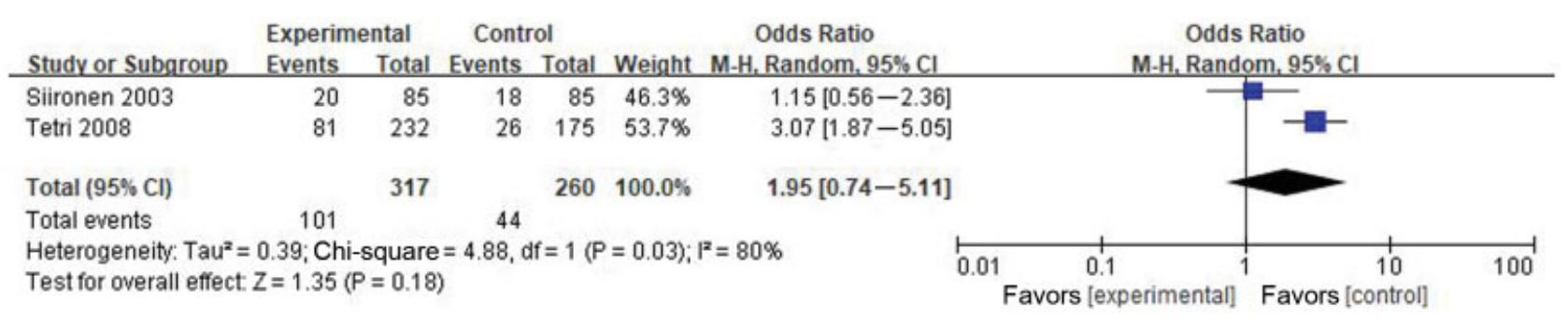

Fig. 6 Major disability at 90 days, according to scores 2 to 3 on the Glasgow Outcome Scale comparing low-molecular-weight heparin or unfractionated heparin with non-heparin treatments (elastic compression stockings, intermitted pneumatic compression, or placebo) for the prevention of venous thromboembolism.

comparison with other treatments, heparin treatment was associated with a nonsignificant increase in the numbers of GOS scores of 2 to 3 (31.9\% versus 16.9\%; RR: 1.95 ; $95 \% \mathrm{CI}$, $0.74-5.11 ; p=0.18)$.

\section{Discussion}

The safety of heparin treatment to prevent VTE in patients with sICH is always controversial largely because of concerns about bleeding, particularly the extension of the ICH and deterioration of neurologic function that would offset any potential benefits of the treatment. ${ }^{17}$ The main conclusion of our analysis across different studies was that prophylactic heparin for VTE might be relatively safe with regard to hematoma enlargement, death, and functional outcome.

Prophylactic heparin for VTE was associated with a nonsignificant increase in hematoma enlargement and a nonsignificant reduction in extracranial hemorrhage. Clinically evident VTE occurs in up to $13 \%$ of patients with sICH, the incidence peaks between days 2 and 7 of hospitalization, and the risk of death from PE is high. ${ }^{27,28}$ The incidence of intracerebral hemorrhage with DVT after initiation of prophylactic heparin may be increased, but this effect is not obvious after late treatment. In radiologic studies and multiple studies, hematoma expansion occurs in 18 to $38 \%$ of patients with sICH within 3 hours, in $70 \%$ within 24 hours, and infrequently after 24 hours. ${ }^{29-31}$ Therefore, in theory, it could be safe to initiate the heparin treatment between days 2 and 7 after ICH onset and cessation of active bleeding. However, blood pressure should be closely monitored during this period because the patient is still at risk for repeated ICH. In comparison, most patients in our studies received heparin within 2 to 7 days after ICH onset. At the same time, computed tomography of the head was repeated more frequently in patients receiving heparin, and this might be a more cautious approach for physicians when administering heparin.

Several observational studies indicated that heparin prophylaxis does not result in hematoma expansion after ICH. In a trial involving 68 patients with $\mathrm{ICH}$, heparin initiation on day 2 led to a statistically lower rate of PE than did initiation on day 4 or day $10 .^{7}$ A more recent trial involving 103 patients demonstrated that subcutaneous enoxaparin does not increase risk of rebleeding or hematoma expansion. ${ }^{8}$ A meta-analysis of four controlled studies ${ }^{6}$ suggested that prophylactic heparin results in a significant reduction in PE, although no effect on bleeding was observed.

The nonsignificance of the reduction in mortality among patients receiving prophylactic heparin in our analysis could be attributed to lower rates of PE and a nonsignificant increase in hematoma enlargement. Our findings were consistent with those of other studies and meta-analyses, showing that prophylactic doses of heparin do not increase mortality after ICH. ${ }^{7,8,10,11,23}$ Standard prophylaxis for patients at high risk includes twice/day dosing with $30 \mathrm{mg}$ enoxaparin. However, previous observations suggested that the incidence of DVT was increased in patients who received $40 \mathrm{mg}$ enoxaparin daily in comparison with a dosage of $30 \mathrm{mg}$ twice/day or lower. ${ }^{32,33}$ Therefore, the use of lower prophylactic doses was considered justified in an attempt to improve outcome after ICH. However, a trial involving 170 patients ${ }^{26}$ demonstrated a higher rate of mortality among the ICH patients who received heparin treatment. Such a higher mortality rate in enoxaparin recipients could be attributed to primary bleeding or rebleeding before enoxaparin treatment and to pneumonia that had nothing to do with heparin treatment.

The major disability, reflected by mRS and GOS scores, of surviving patients among those receiving prophylactic heparin was associated with a nonsignificant increase than those in 
patients not receiving heparin. However, as mentioned, Wurm and colleagues ${ }^{25}$ showed that patients treated with enoxaparin had significantly more favorable GOS scores at 1-year follow-up than patients treated with placebo. Moreover, in experimental mouse models of ischemic stroke, enoxaparin seems to offer good neuroprotection and reduce ischemic lesion size by $49 \%{ }^{34}$ Similarly, Yi et al ${ }^{35}$ showed that LMWH improved outcome in a dose-dependent manner after stroke, as clinically confirmed at 6 months, and was more effective than aspirin alone in preventing early neurologic deterioration and improving the 6-month outcome in patients with ischemic stroke. However, Paula Muñoz-Venturelli et $\mathrm{al}^{23}$ showed that patients who received subcutaneous heparin had greater major disability at 90 days. Major disability was evaluated in only two reports in our study, and there was heterogeneity between those studies. Relevant randomized controlled clinical trials are needed to assess the major disability of prophylactic heparin in patients with sICH.

In addition to the limitations shared by all meta-analyses, our study had some further limitations. On one hand, the sample sizes were small, and most of these studies were of quality "B" or worse, according to the classification scheme of the Centre for Evidence-Based Medicine. On the other hand, anticoagulants include heparin, oral anticoagulants, and thrombin inhibitors. In our study, only the preventive effect of heparin on VTE in sICH was considered. Therefore, large randomized controlled clinical trials are needed to assess the safety of heparin therapy in the prevention of VTE after sICH.

\section{Conclusions}

Our findings indicated that in patients with acute hemorrhagic stroke, prophylactic heparin was associated with a nonsignificant increase in any hematoma enlargement and in mortality, a nonsignificant reduction in extracranial hemorrhage, and a nonsignificant increase in the incidence of major disability in patients with sICH. In clinical practice, prophylactic heparin could be used safely to prevent VTE in patients with $\mathrm{sICH}$. This meta-analysis provided valuable insights into the design of large randomized controlled clinical trials and offers useful information on the safety of prophylactic heparin administration in patients with sICH.

\section{Conflict of Interest}

None declared.

\section{References}

1 Lederle FA, Zylla D, MacDonald R, Wilt TJ. Venous thromboembolism prophylaxis in hospitalized medical patients and those with stroke: a background review for an American College of Physicians Clinical Practice Guideline. Ann Intern Med 2011;155(09): 602-615

2 Gregory PC, Kuhlemeier KV. Prevalence of venous thromboembolism in acute hemorrhagic and thromboembolic stroke. Am J Phys Med Rehabil 2003;82(05):364-369

3 Tapson VF, Decousus H, Pini M, et al; IMPROVE Investigators. Venous thromboembolism prophylaxis in acutely ill hospitalized medical patients: findings from the International Medical Pre- vention Registry on Venous Thromboembolism. Chest 2007;132 (03):936-945

4 Leizorovicz A, Cohen AT, Turpie AG, Olsson CG, Vaitkus PT, Goldhaber SZ; PREVENT Medical Thromboprophylaxis Study Group. Randomized, placebo-controlled trial of dalteparin for the prevention of venous thromboembolism in acutely ill medical patients. Circulation 2004;110(07):874-879

5 Morgenstern LB, Hemphill JC III, Anderson C, et al; American Heart Association Stroke Council and Council on Cardiovascular Nursing. Guidelines for the management of spontaneous intracerebral hemorrhage: a guideline for healthcare professionals from the American Heart Association/American Stroke Association. Stroke 2010;41(09):2108-2129

6 Paciaroni M, Agnelli G, Venti M, Alberti A, Acciarresi M, Caso V. Efficacy and safety of anticoagulants in the prevention of venous thromboembolism in patients with acute cerebral hemorrhage: a meta-analysis of controlled studies. J Thromb Haemost 2011;9 (05):893-898

7 Boeer A, Voth E, Henze T, Prange HW. Early heparin therapy in patients with spontaneous intracerebral haemorrhage. J Neurol Neurosurg Psychiatry 1991;54(05):466-467

8 Hong-chun Y, Wei Y, Li S. The clinical experience for the prevention of thrombosis in deep vein of low limbs in patients with cerebral hemorrhage using low dose of low molecular weight heparin. J Brain Nerv Dis 2015;23:209-301

9 Orken DN, Kenangil G, Ozkurt H, et al. Prevention of deep venous thrombosis and pulmonary embolism in patients with acute intracerebral hemorrhage. Neurologist 2009;15(06):329-331

10 Wasay M, Khan S, Zaki KS, et al. A non-randomized study of safety and efficacy of heparin for DVT prophylaxis in intracerebral haemorrhage. J Pak Med Assoc 2008;58(07):362-364

11 Tetri S, Hakala J, Juvela S, et al. Safety of low-dose subcutaneous enoxaparin for the prevention of venous thromboembolism after primary intracerebral haemorrhage. Thromb Res 2008;123(02): 206-212

12 Steiner T, Al-Shahi Salman R, Beer R, et al; European Stroke Organisation. European Stroke Organisation (ESO) guidelines for the management of spontaneous intracerebral hemorrhage. Int J Stroke 2014;9(07):840-855

13 Hemphill JC III, Greenberg SM, Anderson CS, et al; American Heart Association Stroke Council; Council on Cardiovascular and Stroke Nursing; Council on Clinical Cardiology. Guidelines for the Management of Spontaneous Intracerebral Hemorrhage: A Guideline for Healthcare Professionals from the American Heart Association/ American Stroke Association. Stroke 2015;46(07):2032-2060

14 Higgins JP, Green S. Cochrane Handbook for Systematic Reviews of Interventions, v. 5.0.0 (updated February 2008). London, UK: The Cochrane Collaboration; 2008

15 O'Carroll CB, Capampangan DJ, Aguilar MI, et al. What is the effect of low-molecular weight heparin for venous thromboembolism prophylaxis compared with mechanical methods, on the occurrence of hemorrhagic and venous thromboembolic complications in patients with intracerebral hemorrhage? A critically appraised topic. Neurologist 2011;17(04):232-235

16 Wu TC, Kasam M, Harun N, et al. Pharmacological deep vein thrombosis prophylaxis does not lead to hematoma expansion in intracerebral hemorrhage with intraventricular extension. Stroke 2011;42(03):705-709

17 Kiphuth IC, Staykov D, Köhrmann M, et al. Early administration of low molecular weight heparin after spontaneous intracerebral hemorrhage. A safety analysis. Cerebrovasc Dis 2009;27(02):146-150

18 Pan T, Zhang J, Fan GF, Zhang L. Safety of low molecular weight heparin for the prevention of venous thromboembolism after primary intracerebral haemorrhage. Military Med J Southeast China. 2012;14:517-519

19 Prabhakaran S, Herbers P, Khoury J, et al. Is prophylactic anticoagulation for deep venous thrombosis common practice after intracerebral hemorrhage? Stroke 2015;46(02):369-375 
20 Simard JM, Aldrich EF, Schreibman D, James RF, Polifka A, Beaty N. Low-dose intravenous heparin infusion in patients with aneurysmal subarachnoid hemorrhage: a preliminary assessment. J Neurosurg 2013;119(06):1611-1619

21 Koehler DM, Shipman J, Davidson MA, Guillamondegui O. Is early venous thromboembolism prophylaxis safe in trauma patients with intracranial hemorrhage. J Trauma 2011;70(02):324-329

22 Phelan HA, WolfSE, Norwood SH, et al. A randomized, double-blinded, placebo-controlled pilot trial of anticoagulation in low-risk traumatic brain injury: the Delayed Versus Early Enoxaparin Prophylaxis I (DEEP I) study. J Trauma Acute Care Surg 2012;73(06):1434-1441

23 Muñoz-Venturelli P, Wang X, Lavados PM, et al; INTERACT2 Investigators. Prophylactic heparin in acute intracerebral hemorrhage: a propensity score-matched analysis of the INTERACT2 study. Int J Stroke 2016;11(05):549-556

$24 \mathrm{Gu}$ SS, Zhang J, Han L, et al. Safety of early nadroparin for prevention of deep vein thrombosis in patients with intracerebral hemorrhage. Int J Cerebrovasc Dis 2014;22:902-906

25 Wurm G, Tomancok B, Nussbaumer K, Adelwöhrer C, Holl K. Reduction of ischemic sequelae following spontaneous subarachnoid hemorrhage: a double-blind, randomized comparison of enoxaparin versus placebo. Clin Neurol Neurosurg 2004;106(02):97-103

26 Siironen J, Juvela S, Varis J, et al. No effect of enoxaparin on outcome of aneurysmal subarachnoid hemorrhage: a randomized, double-blind, placebo-controlled clinical trial. J Neurosurg 2003;99(06):953-959

27 Skaf E, Stein PD, Beemath A, Sanchez J, Bustamante MA, Olson RE. Venous thromboembolism in patients with ischemic and hemorrhagic stroke. Am J Cardiol 2005;96(12):1731-1733

28 André C, de Freitas GR, Fukujima MM. Prevention of deep venous thrombosis and pulmonary embolism following stroke: a sys- tematic review of published articles. Eur J Neurol 2007;14(01): 21-32

29 Demchuk AM, Dowlatshahi D, Rodriguez-Luna D, et al; PREDICT/ Sunnybrook ICH CTA study group. Prediction of haematoma growth and outcome in patients with intracerebral haemorrhage using the CT-angiography spot sign (PREDICT): a prospective observational study. Lancet Neurol 2012;11(04):307-314

30 Ovesen C, Christensen AF, Krieger DW, Rosenbaum S, Havsteen I, Christensen $\mathrm{H}$. Time course of early postadmission hematoma expansion in spontaneous intracerebral hemorrhage. Stroke 2014;45(04):994-999

31 Jauch EC, Lindsell CJ, Adeoye O, et al. Lack of evidence for an association between hemodynamic variables and hematoma growth in spontaneous intracerebral hemorrhage. Stroke 2006; 37(08):2061-2065

32 Riha GM, Van PY, Differding JA, Schreiber MA; Oregon Health \& Science University Trauma Research Group. Incidence of deep vein thrombosis is increased with $30 \mathrm{mg}$ twice daily dosing of enoxaparin compared with $40 \mathrm{mg}$ daily. Am J Surg 2012;203(05):598-602

33 Malinoski D, Jafari F, Ewing T, et al. Standard prophylactic enoxaparin dosing leads to inadequate anti-Xa levels and increased deep venous thrombosis rates in critically ill trauma and surgical patients. J Trauma 2010;68(04):874-880

34 Keskin I, Gunal MY, Ayturk N, Kilic U, Ozansoy M, Kilic E. Dosedependent neuroprotective effect of enoxaparin on cold-induced traumatic brain injury. Neural Regen Res 2017;12(05):761-764

35 Yi X, Chi W, Wang C, Zhang B, Lin J. Low-molecular-weight heparin or dual antiplatelet therapy is more effective than aspirin alone in preventing early neurological deterioration and improving the 6month outcome in ischemic stroke patients. J Clin Neurol 2015;11 (01):57-65 